\title{
Unidades de preservación renal experimental. ¿Es necesaria esta actividad en España?
}

\author{
Lledó García E, Rodríguez Martínez D, Cabello Benavente R, Subirá Ríos D, Pedemonte G, \\ Hernández Fernández C, del Cañizo López JF.
}

Servicios de Urología y Medicina-Cirugía Experimental. Hospital General Universitario Gregorio Marañón. Madrid.

Actas Urol Esp. 2008;31(1):24-26

\section{RESUMEN}

UNIDADES DE PRESERVACIÓN RENAL EXPERIMENTAL. ¿ES NECESARIA ESTA ACTIVIDAD EN ESPAÑA?

La investigación en preservación del injerto renal es una actividad complementaria aunque a la vez fundamental en los Programas de Trasplante Renal de calidad. Permite conocer las limitaciones de los riñones que se implantan y descartar aquellos órganos con mayor probabilidad de fracasar. La unificación de criterios en la selección de órganos es esencial. Creemos que este tipo de actividad debe ser estimulada por las instituciones sanitarias, aunque precisa de inversión para técnica y personal.

Palabras clave: Trasplante renal. Investigación. Preservación.

\section{ABSTRACT}

EXPERIMENTAL RENAL PRESERVATION UNITS: ¿IS THIS ACTIVITY NECESSARY IN SPAIN?

Renal graft preservation research is considered complementary but at the same time important activity in high-quality Kidney Transplant Programs. It provides information on limitations of kidneys to be transplanted and to discard those organs with high probability of failure. Unification of criteria in the selection of organs is essential. We think that this activity should be encouraged by Health Institutions although requires investment in staff and technology.

Keywords: Renal trasplantation. Research. Organ preservation.

$\mathrm{E}$ n el año 2005 se registraron en todo el mundo cerca de 95.000 trasplantes de órganos sólidos, de los cuales 65.700 fueron trasplantes de riñón, 21.000 de hígado, 6.000 de corazón y 1.800 de pulmón. A ellos se suman los 9.496 trasplantes de células de progenitores hematopoyéticos (médula ósea) de donante no emparentado.

El 30 de marzo de 2007 se ha presentado el Registro Mundial de Trasplantes, iniciativa coordinada por la Organización Nacional de Trasplantes y la Organización Mundial de la Salud. Esta entidad será, según sus promotores, un punto de referencia para toda la comunidad trasplantadora internacional y recogerá la actividad y resultados de donación y trasplantes de todo el mundo.
En España, la Organización Nacional de Trasplantes ha diseñado un modelo de organización de la donación y consecución de órganos ("modelo español"), que ha sido admirado y exportado al resto del mundo, convirtiéndonos en referencia internacional en el número de trasplantes por población de referencia. En el período 2003-2006 hemos pasado de 1.495 donantes a 1.509 , con un total de implantes renales de 2.125 a 2.157 . Sin embargo, en 2005, de 2.864 riñones generados, se desecharon 716 .

Es un hecho conocido que en los últimos años se ha incrementado la edad media de los donantes. Es un tópico decir que el desarrollo de normas de conducción y seguridad vial, etc, han hecho que disminuyan los llamados "donantes 
óptimos" y que predominen los "subóptimos". Mayor morbilidad vascular, mayor prevalencia de patología asociada (diabetes, hipertensión arterial, hepatitis, etc). Perfiles de donantes que, hace 15 años, eran rechazados, y que en la actualidad debemos aceptar. ¿Sabemos más que antes sobre estos órganos, nos hemos atrevido a implantarlos $\mathrm{y}$ hemos visto que pueden funcionar correctamente o seguimos las tendencias marcadas por grupos de trabajo foráneos?. Disponemos, sin duda de uno de los mejores sistemas extractores del mundo. Nuestros números son fantásticos. Sin embargo, ¿realmente sabemos en cada acto de implante lo que estamos trasplantando?; ¿tomamos decisiones basadas en razones análogas y en una evidencia científica que valdría para cualquier grupo trasplantador?; ¿todos los grupos extractores utilizan unos criterios uniformes de aceptación y rechazo de órganos, unas técnicas de perfusión del cadáver y del órgano similares, los mejores líquidos disponibles de perfusión y conservación?. En definitiva, ¿disponemos de unos criterios homogéneos?. La edad del donante, los factores de comorbilidad, los datos de la biopsia, la creatinina del donante. Cada centro y cada grupo da mayor peso a unos aspectos u otros. ¿Es más importante la biopsia o los datos anexos cronológicos y funcionales?. ¿Por qué no somos capaces de diseñar unos criterios uniformes y nacionales de aceptación y rechazo de órganos?.

La técnica de preservación utilizada puede variar completamente sólo a una distancia de 10 $\mathrm{km}$ entre dos centros. Suponiendo un donante en parada cardiaca, aquel centro que disponga de máquina de perfusión y la utilice, la planteará como el mejor sistema para estos órganos, reportará utilización de la resistencia vascular como el criterio definitivo de aceptación o rechazo del riñón. Sin embargo, el otro centro que no tiene esa tecnología, se basará en la histología, en la información de edad, etc, y con esos datos implantará o rechazará el órgano. Tres mismos hospitales de una sola ciudad pueden utilizar con el mismo tipo de donante distintas soluciones de preservación para los órganos extraídos.

Esta situación, que se produce con el donante de 40 años, el de 60, el hipertenso, el donante a corazón parado, el riñón con glomeruloesclerosis límite... No es la ideal. Se requiere la promoción de mesas de expertos por parte de determinadas organizaciones (la propia O.N.T., la Asociación Española de Urología a través del Coordinador Nacional del Grupo de Trasplante, el Ministerio de Sanidad), que definan unos criterios generales y comunes (o, si nos gusta más, unos Guidelines) sobre la Extracción, Perfusión y Preservación de Riñones (y otros órganos sólidos). La aceptación o rechazo de un órgano no debería ser un concepto que pueda estar sometido a diversas interpretaciones.

Para ello, y en paralelo, es esencial como en cualquier disciplina médica (oncología y biología molecular son claros ejemplos) la investigación. Investigación no solamente en técnica quirúrgica, sino en preservación del órgano a trasplantar. El único test que disponemos actualmente de viabilidad es el propio trasplante, y eso es muy arriesgado. España tiene la suficiente entidad científica en el Trasplante como para disponer de grupos de referencia para toda la realidad nacional que trabajen en técnicas de preservación, desarrollo de criterios de viabilidad, mejoría de las soluciones disponibles de preservación. Ello requiere equipos multidisciplinarios: biólogos, médicos jóvenes (doctorandos) y séniors-nefrólogos, hepatólogos, cardiólogos, cirujanos-. Y, lo que es básico: tiempo e inversión.

La investigación en preservación de órganos no es ni una entelequia ni algo nuevo o propio de países tan ricos que no saben en qué invertir su dinero. Es, fundamentalmente, construir el edificio no sólo fortificando las paredes, sino también los cimientos. Folkert O. Belzer, un médico pionero en el campo del trasplante renal, fundó el Laboratorio de la Universidad de Wisconsin en 1975. En la década de los 80, este Laboratorio patentó una solución de preservación de órganos de calidad e importancia universales: la solución UW-Viaspan ${ }^{\mathrm{R}}$, así como una solución de perfusión hipotérmica de órgano aislado: la solución BelzerMPS $^{R}$. Estas soluciones permitieron cambiar absolutamente el panorama de la preservación y trasplante órganos, especialmente del hígado y páncreas permitiendo el intercambio de los mismos al preservarlos por tiempos de entre 24-48 horas. Sin embargo, y aunque la composición es prácticamente la misma que hace 25 años, sigue habiendo disfunción inicial del injerto. 
El interés primario del laboratorio de preservación debe ser mejorar la calidad de los órganos para el trasplante. Definir unos criterios de viabilidad y trabajar en el diseño de maniobras, especialmente farmacológicas, que puedan atenuar los efectos de la isquemia. El resultado de estos objetivos primarios será la obtención de mejores resultados en cuanto a función primaria de los injertos, y disminuir el número de órganos rechazados. La preservación de órganos implica tres elementos clave: la hipotermia $\left(4^{\circ} \mathrm{C}\right)$ para reducir el metabolismo celular, el diseño o mejora de soluciones impermeables que disminuyan el edema celular y agentes bioquímicos que protejan a la célula contra la agresión isquémica. Existen numerosos campos de la fisiopatología de la lesión celular en los que trabajar: estructura y función de membrana celular, viabilidad tisular y celular, peroxidación lipídica, transporte de calcio, metabolismo fosfolipídico, lesión por reperfusión, hibernación, metabolismo energético, isquemia caliente, factores del donante.

El objetivo último de estos programas de investigación debería ser la mejora de la tecnología de preservación de órganos, que permita una mayor utilización de los donantes disponibles y la consecución de una mejor calidad de los órganos disponibles para los Programas Clínicos de Trasplante. Todo ello redundará en una reducción de costes de los procesos de trasplante, una disminución de las complicaciones, una mejor supervivencia del injerto y del receptor.
Por tanto, a la pregunta de cuál es la necesidad de Unidades de Investigación en Preservación de órganos, no se debe dar una respuesta pasional y poco razonada. Ni si ni no absolutos. Llegados al punto de madurez clínico que se ha conseguido en nuestro Sistema Nacional de Trasplantes de Órganos, utilizándose técnicas quirúrgicas de mínima invasividad como la laparoscopia para la extracción de órganos, estas Unidades son convenientes, adecuadas al número de implantes que se realizan en nuestro país, deberian estar ubicadas en determinados centro de referencia, y completamente coordinadas con Programas Clínicos. Esta investigación "traslacional", en la que se complementen con armonía el laboratorio, el clínico y el quirófano, permitirá obtener una profunda y completa comprensión del trasplante distinta a la proporcionada por el número de órganos obtenidos e implantados o por la técnica quirúrgica empleada.

\section{REFERENCIAS}

1. Página WEB de la ONT: www.ONT.es. 2007.

2. Nota de Prensa - Ministerio de Sanidad y Consumo - 30 de Marzo de 2007 (www.msc.es).

3. Página Web de Universidad de Wisconsin - Laboratorio de Preservación de Organos (http://www.surgery.wisc.edu/ transplant/faculty/southard.shtml).

Correspondencia autor: Dr. E. Lledó García Servicio de Urología.

Hospital General Universitario Gregorio Marañón

Doctor Esquerdo, 46 - 28007 Madrid

Tel.: 915868000

E-mail autor: ENLLGA@terra.es

Información artículo: Original 